\title{
Sacro-coccygeal Epidermoid Cyst: A Case Report from Tertiary Care Centre in India
}

\author{
Dr. Amit Jain ${ }^{1}$, Dr. Shubham Singhal ${ }^{2 *}$, Dr. Neeraj Damor ${ }^{2}$
}

${ }_{1}^{1}$ Professor, Department of General Surgery, SMS Medical College, Jaipur, Rajasthan, India
${ }^{2}$ Resident Doctor, Department of General Surgery, SMS Medical College, Jaipur, Rajasthan, India

DOI: $10.36347 /$ sasjs.2022.v08i01.002

| Received: 01.12.2021 | Accepted: 04.01.2022 | Published: 07.01.2022

*Corresponding author: Dr. Shubham Singhal

Resident Doctor, Department of General Surgery, SMS Medical College, Jaipur, Rajasthan, India

\section{Abstract}

Localization of primitive neoplasms the retrorectal or presacral space is rare in adults as most of these tumors are congenital. Developmental cysts are included within the group of retrorectal congenital cystic neoplasms and are slowly-progressive cystic neoplasms. Because of their localization, their manifestation is delayed, despite their congenital nature. Their form of presentation is varied and is caused by compression of the surrounding organs or infectious complications of the cyst. In the present case, we have $55 \mathrm{yr}$ old female with complain of low back painand pus dyscharge from perineal region. Further examination reveal $84 * 54 * 49 \mathrm{~mm}$ lesion in posterior perianal region on either side of natal cleft with cutaneous opening within natal cleft. Post operative biopsy suggestive of epidermoid cyst.

Keywords: Epidermoid cyst, transsacral.

Copyright $\odot 2022$ The Author(s): This is an open-access article distributed under the terms of the Creative Commons Attribution 4.0 International License (CC BY-NC 4.0) which permits unrestricted use, distribution, and reproduction in any medium for non-commercial use provided the original author and source are credited.

\section{INTRODUCTION}

Epidermoid cyst is considered benign lesion that usually affect the scalp regions, face, neck, back, and torso. It is commonly asymptomatic, however, it may become symptomatic due to secondary infection or when it reaches dimensions that can cause damage to the surrounding anatomical structures [1]. It can develop in any part of the body; it has a slow growth and is rare. $7 \%$ of these cysts occur in the head and neck, oral cavity representing only $1.6 \%$ [2]. These skin structures are represented by hair, sebaceous glands, hair follicles, and sweat glands. Epidermoid cysts are either congenital or acquired [3]. They can develop in isolation or multifocal form, as can be seen in Gardner's syndrome. Surgical enucleation if the recommended treatment for epidermoid cysts [4].

\section{CASE REPORT}

A $55 \mathrm{yr}$ old female presented to us with chief complaints of lower back region for 3 year that was gradual in onset, dull aching and intermittent subsided on medication, not radiating, non-progressive. Pt also have complain of pus discharge from perianal region for last 1 year no h/o Per rectal bleed, no h/o pruritis, no h/o $\mathrm{p} / \mathrm{r}$ pain during defaecation, no $\mathrm{h} / \mathrm{o} \mathrm{P} / \mathrm{R}$ itching, no $\mathrm{h} / \mathrm{o}$ diarrhea, no h/o mucus discharge. Patient has history of surgery for pilonidal sinus 3 year back and h/o constipation.

On per rectal examination there is previous scar mark is present, an external opening at 5 o clock and an external opening seen in natal cleft and hair are present in the cleft (Fig 1).

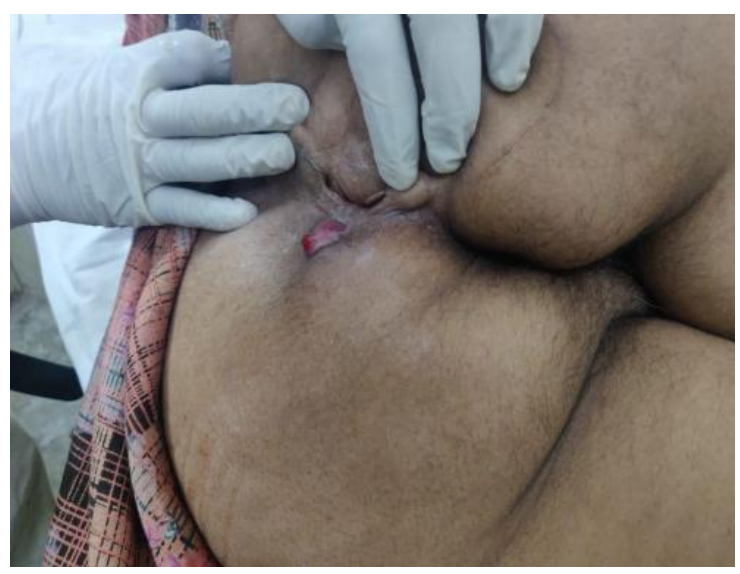

Fig 1

CECT reveals? partially calcified organized abscess in presacral pre - coccygeal region with fistula formation with total lesion measures $7 * 10.3 * 9.5 \mathrm{~cm}$ in 
size and inferiorly it communicate with fistulous tract in midline.

MRI reveals- A fairly large collection measuring $84 * 54 * 49 * \mathrm{~mm}$ in posterior perianal region on either side of natal cleft with suggestion of a cutaneous openening within the natal cleft. There is multi-septated intrapelvic presacral lesion extending into right obturator foramen. No communication with anal canal and rectum is seen (Fig 2-5).

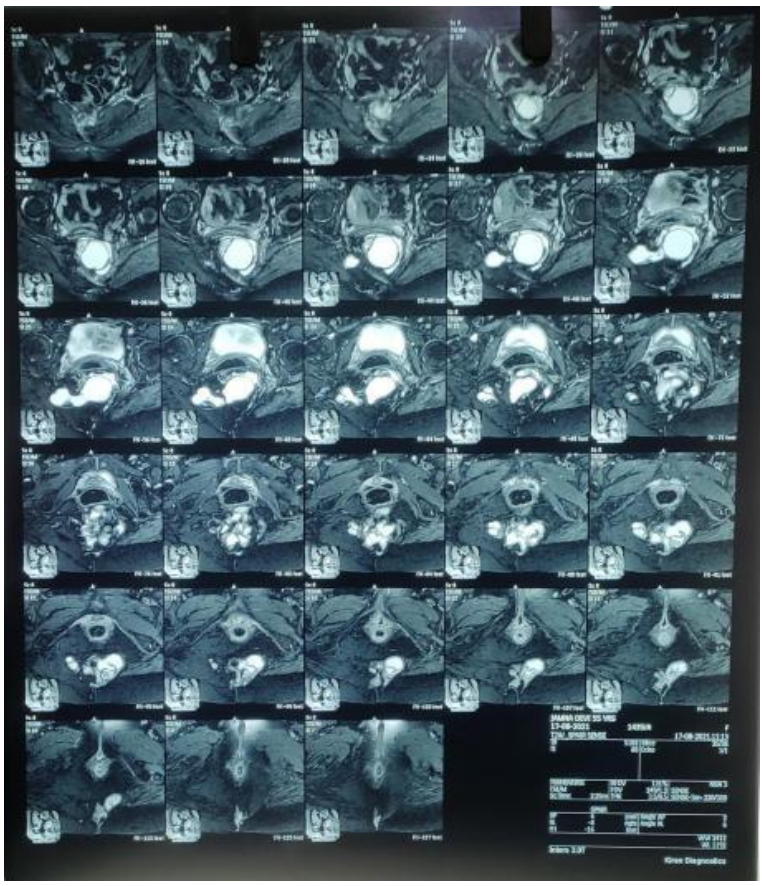

Fig 2

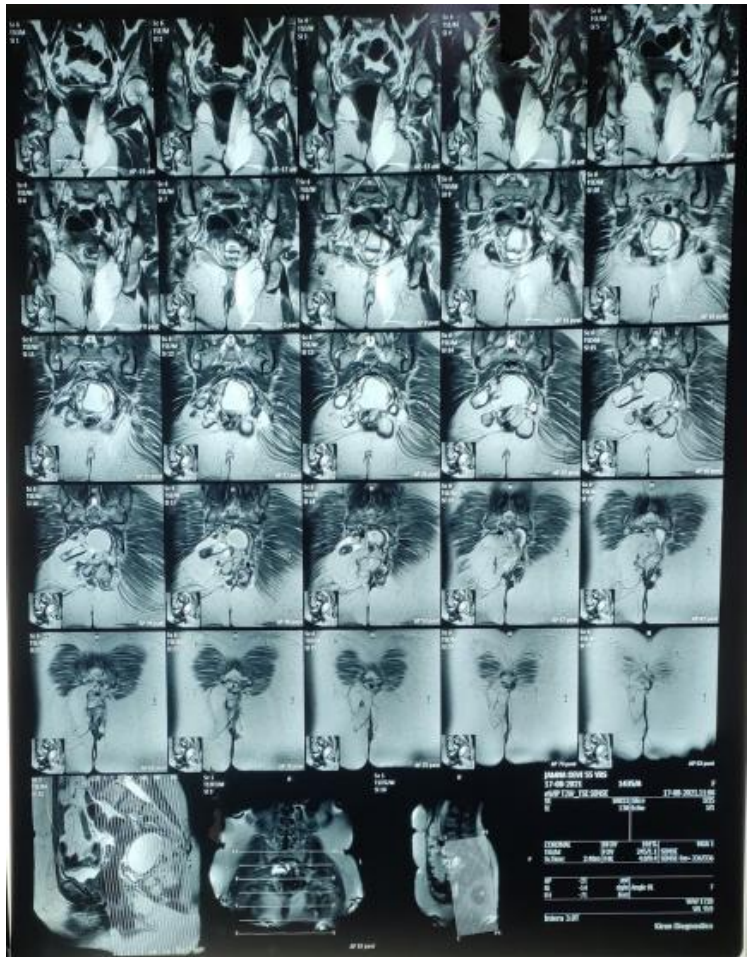

Fig 3

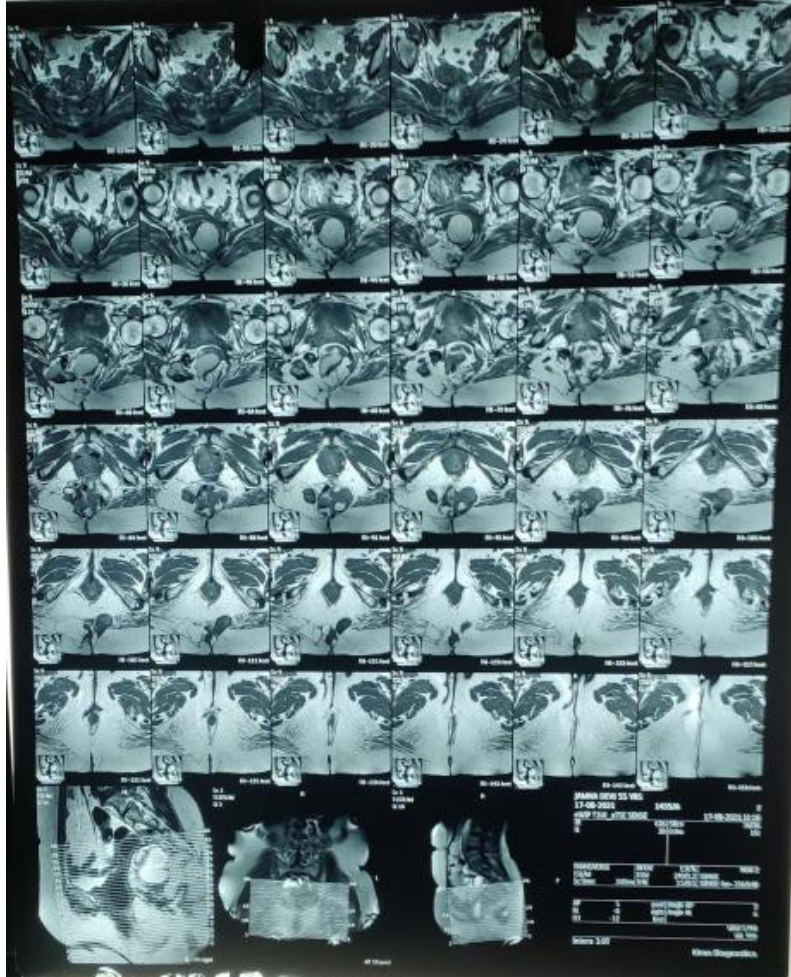

Fig 4

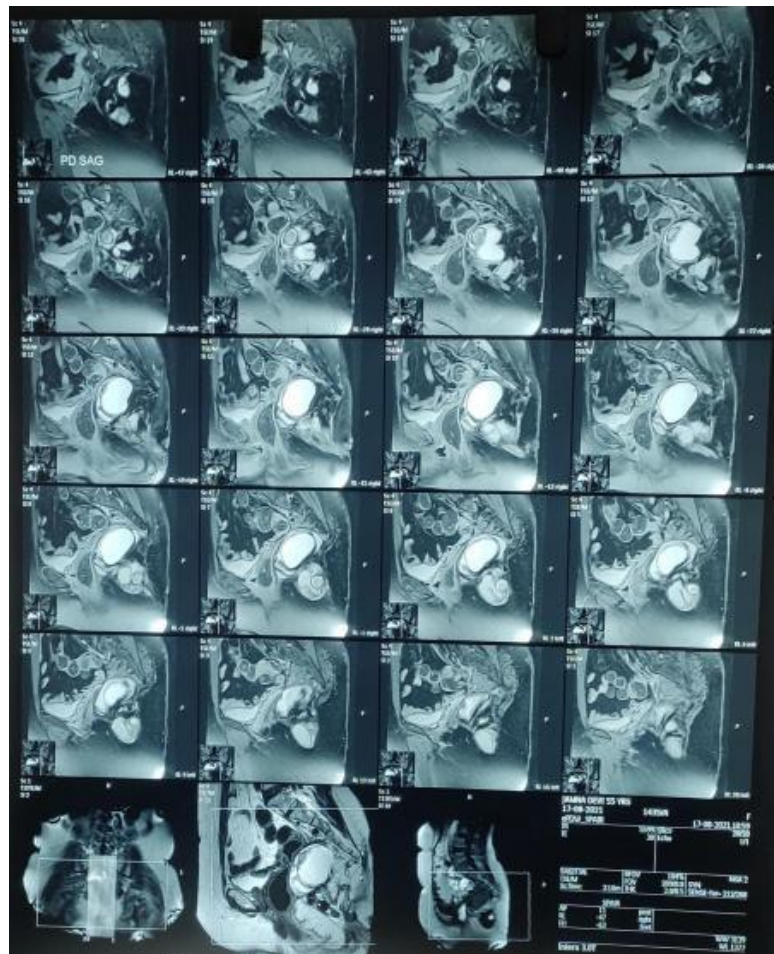

Fig 5

Operative Procedure -Large sacrococcygeal sinus at 5 o clock and natal cleft with $\sim 50 \mathrm{cc}$ of pus is present, sinus was involving the coccyx. Pus was drained and all fistulous tract excised. A negative drain is palced in excised cavity. No connection with anal canal or rectum is seen. Skin is closed in layer (Fig 6). 


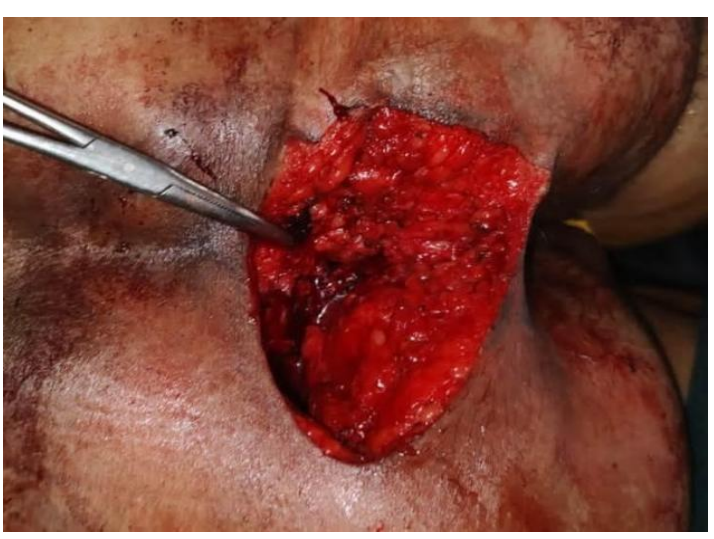

Fig 6

\section{DISCUSSION}

The presacral space, which contains different types of embryonic tissue, is a potential site for several tumors including epidermoid cyst. Presacral cysts are divided into two major groups: teratomas and developmental cysts. Presacral developmental cysts are rare congenital injuries with significant manifestations in the adult. The generally accepted definition in describing an epidermoid cyst is as follows: an epidermoid cyst has stratified squamous epithelium with keratohyaline granules, but no skin appendages [5]. Most patients with presacral tumors complain of nonspecific symptoms. To confirm the diagnosis of a presacral tumor, CT or MRI should be performed. A preoperative biopsy is unnecessary and is actually contraindicated for operable lesions. When our case, along with the 9 other cases of presacral epidermoid cysts documented in the Japanese literature, were analyzed [6-14], it was revealed that 3 were operated on by the abdominal approach, 5 by the transsacral approach, and none through the combined approach (Table 1).

Table 1: Clinical profiles of patients with presacral epidermoid cysts documented in the Japanese

\begin{tabular}{|l|l|l|l|l|}
\hline Sr. no & First author ref. & Age & Sex & Approach \\
\hline 1 & Yamamoto [6] & 45 & F & Transsacral \\
\hline 2 & Kato [7] & 14 & F & Abdominal \\
\hline 3 & Shimanuki [8] & 30 & F & Abdominal \\
\hline 4 & Izumi [9] & 49 & M & Transsacral \\
\hline 5 & Shibata [10] & 37 & F & Transsacral \\
\hline 6 & Usui [11] & 51 & F & Abdominal \\
\hline 7 & Hirai [12] & 46 & F & Transretroperitoneal \\
\hline 8 & Tanaka [13] & 54 & F & Transsacral \\
\hline 9 & Odaka [14] & 64 & F & Transacral \\
\hline
\end{tabular}

\section{CONCLUSION}

Sacrococcygeal epidermoid cyst is a rare case, and trans-sacral approach is most commonly employed. We excised it bby trans-sacral approach and no recurrence noted after 8 month of follow up.

\section{REFERENCES}

1. Park, T. W., Kim, J. K., \& Kimb, J. R. (2014). Giant epidermal cyst in the posterior neck developing over 40 years: A case report. Experimental and therapeutic medicine, 7(1), 287-289.

2. Janarthanam, J., \& Mahadevan, S. (2012). Epidermoid cyst of submandibular region. Journal of oral and maxillofacial pathology: JOMFP, 16(3), 435.

3. de Mendonça, J. C. G., Jardim, E. C. G., Dos Santos, C. M., Masocatto, D. C., de Quadros, D. C., Oliveira, M. M., ... \& Teixeira, F. R. (2017). Epidermoid cyst: clinical and surgical case report. Annals of maxillofacial surgery, 7(1), 151.

4. Tancredi, A. R. C., Ribeiro-Júnior, O., Higo, C. D., Pedron, I. G., \& Lemos-Júnior, C. A. (2006). Epidermoid cyst in the labial comissure region: Case report. Clin Pesq Odontol, 2, 329-332.

5. Jao, S. W., \& Beart Jr, R. W. (1960). Jr, Spencer RJ, Reiman HM, Ilstrup DM. Retrorectal tumors. Mayo Clinic experience, 1979, 644-652.

6. Yamamoto, M. (1937). A case of sacral epidermoid cyst. J Jpn Surg Cos, 38, 355.
7. Kato, Y. (1981). A case of presacral epidermal cyst accompanying malformation of urogenital structure in the left side. Sanka to Fujinka (Gynecol Obstet), 48, 1530-1534.

8. Shimanuki, K., Kasahara, K., Aoyagi, Y., Konishi, F., Kanazawa, K., \& Hirota, N. (1984). A case of presacral epidermoid cyst in the adult. The journal of the Japanese Practical Surgeon Society, 45(7), 983-986.

9. Izumi, T. (1986). A case of epidemoid cyst developed at presacral space. Nihon Rinshou Geka Gakkai Zasshi (Jpn $J$ Clin Surg), 47, 702.

10. Ueda, K., Tsunoda, A., Nakamura, A., Kobayashi, H., Shimizu, Y., Kusano, M., \& Ohta, H. (1998). Presacral epidermoid cyst: report of a case. Surgery today, 28(6), 665-668.

11. Usui, Y., Sasaki, S., Kayano, K., Okada, T., Kojoh, T., Ikeda, T., ... \& Nishi, S. (1988). Two cases of adult presacral tumor. The journal of the Japanese Practical Surgeon Society, 49(8), 1469-1473.

12. Hirai, S. (1993). A case of presacral tumor in an adult. Geka (Surgery), 55, 708-710.

13. Tanaka, K. I., Nakamura, T., Nakae, S., Yoshioka, H., Shiraishi, T., Ikegawa, R., ... \& Saito, Y. (1995). A case of adult presacral epidermoid cyst. The journal of the Japanese Practical Surgeon Society, 56(7), 1478-1482.

14. Odaka, A., Fujioka, M., Kobayashi, M., \& Kanamaru, H. (1994). Two cases of adult presacral tumor. Nippon Daicho Komonbyo Gakkai Zasshi, 47(1), 86-91. 